\title{
Evidence for Developmentally Regulated Local Translation of Odorant Receptor mRNAs in the Axons of Olfactory Sensory Neurons
}

\author{
Caroline Dubacq, ${ }^{1,2}$ Sophie Jamet, ${ }^{1,2}$ and Alain Trembleau ${ }^{1,2}$ \\ ${ }^{1}$ Avenir/Inserm and Fondation pour la Recherche Médicale Team “Development and Plasticity of Neural Networks," Université Pierre et Marie Curie \\ (UPMC), Unité Mixte de Recherche (UMR) 7102, and 2Centre National de la Recherche Scientifique, UMR 7102, F-75005 Paris, France
}

\begin{abstract}
Odorant receptor mRNAs are transported within axons of olfactory sensory neurons that project into the olfactory bulb. Odorant receptor proteins have been identified along the distal part of these axons, which raises the possibility of their local synthesis in axons. We took advantage of the anatomical separation between the olfactory mucosa (which contains the sensory neuron cell bodies) and the bulb (which contains sensory axons but no sensory neuron cell bodies) to address this issue using a quantitative biochemical approach. Combining a method that separates polysome-associated mRNAs from untranslated mRNAs with a reverse transcription- quantitative PCR approach, we demonstrate that significant amounts of odorant receptor mRNAs are associated with polysomes in the sensory axons of the adult mouse bulb. We thus provide the first evidence for local synthesis of odorant receptor proteins in these axons. Interestingly, the rate of odorant receptor mRNA translation in axons is significantly greater during periods when the proportion of immature axons is higher (i.e., at postnatal day 4 or on regeneration after chemical lesion in adults). In contrast, the olfactory marker protein mRNA, which is restricted to mature axons, is translated at a low and constant level. Overall, we demonstrate that translation levels of odorant receptor mRNAs in axons are developmentally regulated, and positively correlated to the stage of axonal growth into the bulb. Given the established function of odorant receptors in the axonal wiring of sensory projections, we propose that this regulated axonal translation may play a role in the development and maintenance of the glomerular array.
\end{abstract}

\section{Introduction}

Regulated local translation in axons plays key roles in orchestrating neuronal network development and affecting plasticity in vertebrates. Such roles include axon guidance (Lin and Holt, 2007), viability (Hillefors et al., 2007), regeneration (Willis and Twiss, 2006), and neuronal survival (Cox et al., 2008). For example, in embryonic rat dorsal root ganglia neurons, Semaphorin 3A-induced local translation of RhoA mRNA is necessary and sufficient for growth cone collapse (Wu et al., 2005). In various neuronal preparations, cue-dependent local translation of mRNAs in growth cones seems to be necessary for the attractive or repulsive actions of guidance cues (Campbell and Holt, 2001; Brunet et al., 2005; Leung et al., 2006; Yao et al., 2006), although it may not be

Received May 21, 2009; revised July 7, 2009; accepted July 10, 2009.

This work was supported by Centre National de la Recherche Scientifique, Université Pierre et Marie Curie (UPMC), Institut du Cerveau et de la Moelle Épinière, Inserm Avenir Program Grant R06496DS, Agence Nationale de la Recherche Grant 06-NEUR-039-01, and Fondation pour la Recherche Médicale Grants INE20071110908 and DEQ20071210561. This team is affiliated with the Paris School of Neuroscience (École des Neurosciences de Paris Île-de-France). We thank Alain Prochiantz for generously providing access to his laboratory for some of these experiments and for his helpful advice, Isabelle Caillé for her scientific insights, Stéphane Nédélec for his helpful input, Samuel Bornens (Institut Fédératif de Recherche des Sciences 83, UPMC, Paris, France) for his help with the qPCR analyses, Franck Margolis for providing the anti-OMP antibody, and David Mou for critical reading of this manuscript.

Correspondence should be addressed to Alain Trembleau, Avenir/Inserm Team, Centre National de la Recherche Scientifique, Unité Mixte de Recherche 7102, Université Pierre et Marie Curie, Boîte 12, 9 quai Saint Bernard, 75252

Paris Cedex 05, France. E-mail: alain.trembleau@upmc.fr.

DOI:10.1523/JNEUROSCI.2443-09.2009

Copyright $\odot 2009$ Society for Neuroscience $\quad$ 0270-6474/09/2910184-07\$15.00/0 required in certain circumstances (Roche et al., 2009). Remarkably, local translation of the ephrin receptor EphA2 is activated in commissural neurons growth cones as they cross the midline, a phenomenon that is likely involved in their change in responsiveness to guidance cues at this intermediate target (Brittis et al., 2002). Additional reports also confirm the existence of mRNAs and their translation in mature axons of vertebrates (for review, see Giuditta et al., 2008).

Along with the adult hypothalamo-neurohypophyseal secretory neurons, adult mouse olfactory sensory neurons were among the first vertebrate neurons in which specific mRNAs were unambiguously identified in the axonal compartment in vivo (Ressler et al., 1994; Trembleau et al., 1994; Vassar et al., 1994). Soon after the cloning of odorant receptors, studies using radioactive in situ hybridization showed that these mRNAs are present in sensory axon terminals in the adult olfactory bulb (Ressler et al., 1994; Vassar et al., 1994). Because of the continuous neurogenesis that occurs in the adult olfactory epithelium (Mackay-Sim and Kittel, 1991), growing immature axons coexist with mature axons in the adult olfactory bulb. Given the low resolution of radioactive in situ hybridization, the maturity of the odorant receptor mRNA-containing axons could not be assessed. However, it is known that the olfactory marker protein (OMP) is expressed only by mature sensory neurons and that its mRNA is found axonally, which demonstrates that mature axons have the ability to transport mRNA (Vassar et al., 1994; Wensley et al., 1995). No evidence for the translation of odorant receptor or OMP mRNAs 
in sensory neuron axons has been reported thus far. Of particular interest, however, we have shown that the Emx2 homeodomain transcription factor is also transported into olfactory axons, where it interacts with the eIF4E translation initiation factor, a feature that suggests a regulated translation of mRNAs in these axons (Nédélec et al., 2004, 2005). Furthermore, the observation of endogenous odorant receptors in the most distal segments of sensory axons within the olfactory bulb, but not in intermediate axon bundles connecting the epithelium to the bulb (Barnea et al., 2004; Strotmann et al., 2004), raises the question as to what molecular mechanisms control this intriguing axonal compartmentalization. These latter observations prompted us to investigate the local translation of odorant receptor mRNAs in olfactory sensory axons.

\section{Materials and Methods}

Animals and experimental treatment. SWISS mice (CERJanvier) at ages 2 month (adult) and $4 \mathrm{~d}$ postnatal (P4) were used. Both female and male $\mathrm{P} 4$ mice were used, whereas all adult mice were males.

Chemical lesions of the olfactory sensory neurons were obtained by three intraperitoneal injections of dichlobenil (Fluka; $25 \mathrm{mg} / \mathrm{kg}$ body weight) dissolved in dimethylsulfoxide (DMSO) (Sigma-Aldrich), performed on days 0, 2, and 4 (Yoon et al., 2005). DMSO intraperitoneal injection had no visible effect onto olfactory epithelium (data not shown). Experiments involving animals were approved by the Regional Ethic Committee for Animal Handling (Comité Régional d'Ethique pour l'Expérimentation Animale Île-de-France).

$R N A$ extraction from tissues and quantitative reverse transcription- $P C R$ amplification. Mice were killed, and the olfactory mucosa or the olfactory bulbs were dissected and either directly homogenized in QIAzol lysis reagent with a rotor-stator homogenizer, or frozen at $-80^{\circ} \mathrm{C}$ before homogenization. Total RNAs were isolated using the RNeasy or RNeasy Lipid Tissue kit (QIAGEN) according to the procedures indicated by the manufacturer. One hundred nanograms to $1 \mu \mathrm{g}$ of total RNA extracted from crude olfactory tissues was used as template for reverse transcription with the QuantiTect reverse transcription (RT) kit (QIAGEN). A volume of $2.5 \mu \mathrm{l}$ (one-eighth of the total RT volume) of the resulting cDNA was immediately used as a template for quantitative PCR (qPCR). qPCR was performed in the Icycler detection system (Bio-Rad) using the ABsolute SYBR Green QPCR kit (ABgene). A typical run included an initial denaturation step $\left(95^{\circ} \mathrm{C} ; 13.5 \mathrm{~min}\right)$ to activate the polymerase, 50 cycles with a $95^{\circ} \mathrm{C}$ denaturation for $15 \mathrm{~s}, 57^{\circ} \mathrm{C}$ annealing and $30 \mathrm{~s}, 72^{\circ} \mathrm{C}$ extension, and then a melting curve data collection. Primers were designed to improve the amplification efficiency (for primer sequence and efficiency, see supplemental material, available at www.jneurosci.org) and used at optimized concentration of $300 \mathrm{~nm}$ (in a $25 \mu$ l total reaction volume). Primers were chosen in the coding sequence of genes, except for the MOR10 primer pair, which was designed into the $5^{\prime}$-untranslated region (exon 1) of the gene since the coding sequences of MOR2 8 and MOR10 genes share $92 \%$ identity. All primer pairs used in this study amplified a single specific product (no primer dimer formation). Negative controls without reverse transcription and without any template were tested for each sample to ensure that no product was obtained. Each cDNA sample was amplified in triplicate. Threshold was fixed using the maximum correlation coefficient approach. Absolute mRNA quantities were normalized with $\alpha 1 \mathrm{~b}$-Tubulin mRNA used as a standard to assess relative quantities of mRNAs.

Immunofluorescence. Anesthetized mice were fixed by intracardiac perfusion of $4 \%$ paraformaldehyde. Tissues were dissected and postfixed for $1 \mathrm{~h}$ at $4^{\circ} \mathrm{C}$ with the same fixative, rinsed with $0.1 \mathrm{M} \mathrm{PBS}$, and cryoprotected overnight in $15 \%$ sucrose diluted in $0.1 \mathrm{M}$ phosphate buffer. Fourteen-micrometer cryostat sections were saturated in blocking solution ( $1 \times$ PBS, $0.2 \%$ Triton X-100, 5\% FCS, $0.5 \%$ BSA) and incubated overnight at $4^{\circ} \mathrm{C}$ in goat anti-OMP (provided by F. Margolis, University of Maryland, Baltimore, MD; $1 / 2000$ ) and mouse monoclonal anti- $\beta$ IIItubulin (TUJ1 from Abcam; 1/1000) antibodies. The secondary antibodies used were Cy3-conjugated donkey anti-goat and FITC-conjugated
Table 1. Assessment of axonal odorant receptor mRNAs in adult mice olfactory system

\begin{tabular}{lcrr}
\hline & \multicolumn{4}{l}{$\begin{array}{l}\text { mRNA relative quantity }\left(10^{-3}\right) \\
(\alpha 1 \mathrm{~b}-\text { Tubulin normalization })\end{array}$} \\
\cline { 2 - 4 } & \multicolumn{1}{c}{ MOR253-5 } & \multicolumn{1}{c}{ MOR10 } & \multicolumn{1}{c}{ MOR83 } \\
\hline Olfactory bulb & $0.05 \pm 0.01$ & $0.08 \pm 0.02$ & $0.07 \pm 0.01$ \\
Olfactory epithelium & $39.77 \pm 4.77$ & $25.52 \pm 4.92$ & $24.02 \pm 4.57$ \\
\hline
\end{tabular}

RT-qPCR quantification of three odorant receptor mRNAs in adult mouse olfactory bulb and epithelium. Data are expressed as mean \pm SEM $(n=4)$.

donkey anti-mouse (Jackson ImmunoResearch Laboratories). Sections were also stained with 4',6'-diamidino-2-phenylindole (DAPI).

Polysome preparation and analysis. Twenty to $100 \mathrm{mg}$ of fresh tissues were homogenized in lysis buffer [ $30 \mathrm{~mm}$ Tris, $\mathrm{pH} 7.5,100 \mathrm{~mm} \mathrm{NaCl}$, $10-20 \mathrm{~mm} \mathrm{MgCl}_{2}, 0.3 \%$ Triton X-100, 1 mm DTT, $1 \times$ Complete protease inhibitors without EDTA (Roche), $40-80 \mathrm{U} / \mathrm{ml}$ Rnasin (Promega), and $100 \mu \mathrm{g} / \mathrm{ml}$ cycloheximide] using a Dounce homogenizer. After $15 \mathrm{~min}$ of incubation on ice, the lysates were centrifuged at $12,000 \times g$ for $8 \mathrm{~min}$ at $4^{\circ} \mathrm{C}$. The supernatant was immediately sedimented in a $5-60 \%(\mathrm{w} / \mathrm{v})$ sucrose gradient by centrifugation at $190,000 \times g$ for $1 \mathrm{~h}$. Each gradient was collected in 12 fractions while absorbance was monitored at $254 \mathrm{~nm}$. Polysomal and messenger ribonucleoprotein (mRNP) fractions identified from the absorbance profile were pooled into two different tubes before RNA extraction. All of the RNA was isolated from these samples using TRIzol LS reagent (Invitrogen), before being further purified using the RNeasy Mini kit (QIAGEN) following the manufacturer's recommendations. Fractionation and purification were validated by agarose gel electrophoresis migration of the purified RNAs. A volume of $10 \mu$ l (onesixth of the total elution volume) of total RNA extracted from polysome or mRNP fractions was used for RT-qPCR experiments as described above.

Statistical analyses. Data analysis was conducted using the nonparametric Mann-Whitney $U$ test on the XLSTAT software.

\section{Results}

The adult mouse olfactory epithelium contains several million olfactory sensory neurons (Mori et al., 1999), each of which expresses one allele of a single odorant receptor gene out of a repertoire of >1000 genes (Buck and Axel, 1991; Mombaerts, 2004; Zhang et al., 2004). Each olfactory sensory neuron projects a single, unbranched axon into a single glomerulus of the olfactory bulb (Klenoff and Greer, 1998). Hence, a given odorant receptor mRNA is expressed by only a few thousand sensory neurons and only a few thousand axon terminal segments containing these odorant receptor mRNAs are present in the bulb. To study the association of axonal odorant receptor mRNAs with polysomes in vivo, we needed to be able to quantify these individual mRNAs, despite the fact that they represented only a minute fraction of all olfactory bulb RNAs. We therefore used a RT-qPCR assay to test several primers for various odorant receptor mRNAs known to be highly expressed in the olfactory epithelium (Tsuboi et al., 1999; Zhang et al., 2004). We obtained three satisfactory pairs of primers, selected for their specificity, efficiency, and sensitivity, which allowed for the accurate quantification of MOR253-5, MOR10, and MOR83 mRNAs from adult mouse bulb total RNA (supplemental Table 1, available at www.jneurosci.org as supplemental material). Using these primers, we were able to quantify MOR253-5, MOR83, and MOR10 mRNAs in extracts from adult olfactory epithelium and bulb with the $\alpha 1 \mathrm{~b}$-Tubulin somatic mRNA as a standard for normalization (Table 1). As expected, the ratio between odorant receptor mRNAs and $\alpha 1 \mathrm{~b}$-Tubulin mRNA is much higher $(\sim 1 / 25$ to $1 / 42$ depending on the odorant receptor) in the epithelium than in the bulb (between $1 / 12,500$ to $1 / 20,000$, depending on the odorant receptor). To confirm that the low odorant receptor mRNA RT-qPCR signals obtained in 

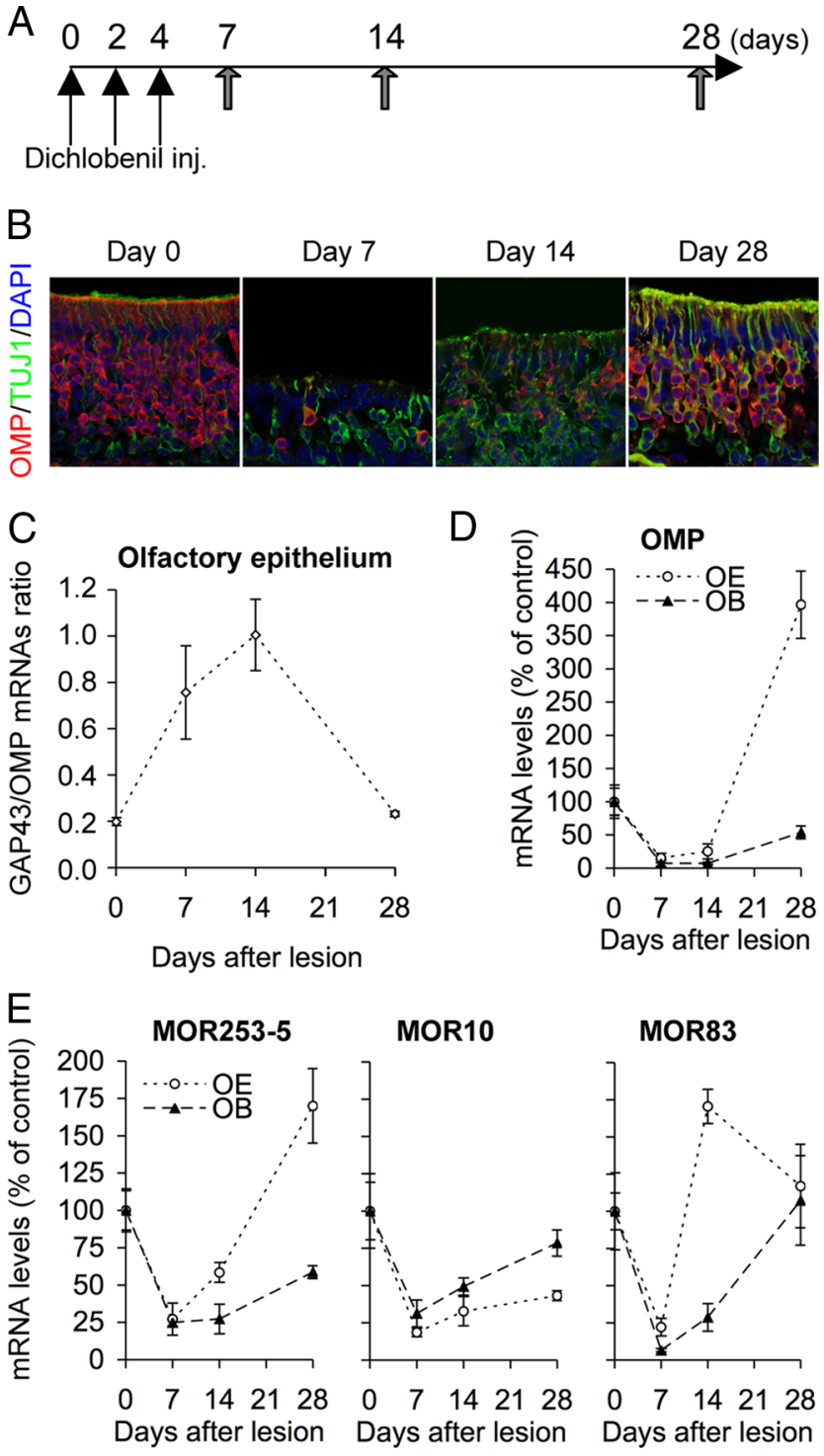

Figure 1. Assessment of axonal odorant receptor mRNAs in adult mice olfactory bulb during reversible sensory deafferentation. $A$, Protocol of chemical lesion of olfactory sensory neurons: intraperitoneal injections of dichlobenil were performed at days 0,2 , and 4 in adult mice; mice were killed at days 7, 14, or 28. $\boldsymbol{B}$, Immunolocalization of OMP (a specific marker for mature olfactory sensory neurons; red label) and $\beta$ III-Tubulin (a marker for immature neurons - TUJ1 antibody; green label) in the olfactory epithelium after dichlobenil treatment. Blue label (DAPI) stains cell nuclei. At day 7, few 0MP-positive neurons remain in the lesioned olfactory epithelium characterized by a dramatically reduced thickness. However, the lesion triggers the regeneration of new sensory neurons, which were initially TUJ1-immunoreactive before they progressively mature to become OMP-expressing neurons. $\boldsymbol{C}$, The ratio between GAP43 mRNA (a marker for immature neurons) and OMP mRNA is transiently increased in the olfactory epithelium, further demonstrating the strong regeneration of sensory neurons $1-2$ weeks after the onset of the lesion. $\boldsymbol{D}, \boldsymbol{E}, \mathrm{RT}-\mathrm{qPCR}$ assessment of OMP $(\boldsymbol{D})$ and odorant receptors $(\boldsymbol{E})$ mRNAs in olfactory bulb $(O B)$ and olfactory epithelium $(O E)$ on dichlobenil treatment. mRNA levels represent the percentage of measured mRNAs compared with that in untreated mice. $D$, Dichlobenil treatment induces a dramatic decrease in OMP mRNA contents in the $O E$ and in the $O B$ at days 7 and 14, which subsequently increases as the epithelium regenerates, indicating that OMP mRNA molecules measured in the bulb originated in the axons. $\boldsymbol{E}$, Similarly, dichlobenil treatment induces a dramatic decrease in odorant receptor mRNA contents in the olfactory epithelium and bulb at day 7 , which subsequently increases, indicating that odorant receptor mRNAs measured in the bulb likewise originated in the axons. Data are expressed as mean \pm SEM $(n=3-5)$. RT-qPCR data in $\boldsymbol{D}$ and $\boldsymbol{E}$ were normalized using $\alpha 1 \mathrm{~b}$-Tubulin mRNA as an internal standard. olfactory bulb is of axonal origin rather than that of expression from olfactory bulb sources, we verified that sensory deafferentation of the bulb leads to decreased amounts of odorant receptor mRNAs in this tissue. For this purpose, we performed dichlobenil treatments, which specifically kills olfactory sensory neurons (Yoon et al., 2005).

In agreement with previous reports (Yoon et al., 2005), we observed a dramatic loss of OMP-expressing sensory neurons within the olfactory epithelium after intraperitoneal injections of dichlobenil (Fig. 1 A). The loss peaked $7 \mathrm{~d}$ after the first intraperitoneal injection (Fig. 1B). After chemical lesions, new sensory neurons are generated (Fig. 1B, TUJ1-labeled cells), which progressively mature and reinnervate the olfactory bulb (Schwob, 2005). Such chemical treatments are subject to variation among different samples. However, the overall ratio of GAP43 mRNA (specifically expressed by immature sensory neurons) to OMP mRNA demonstrates the transient lesion/regeneration process induced by the dichlobenil lesion (Fig. 1C). Remarkably, the dramatic decrease in OMP mRNA in the olfactory epithelium at day 7 and day 14 was correlated to a similar decrease in the olfactory bulb, demonstrating that the OMP mRNA detected in the bulb was of sensory neuron axonal origin (Fig. $1 D$ ). Likewise, the amount of odorant receptor mRNA dramatically declined in the epithelium 1 week after the onset of treatment, followed by an increase during the 3 subsequent weeks (Fig. 1E). Very importantly, a similar phenomenon was observed in the olfactory bulb: although a dramatic decrease in odorant receptor mRNAs was observed at day 7 , a progressive increase occurred between day 7 and day 28 , as expected for mRNAs that are transported in sensory neuron axons as they grow into the bulb (Fig. $1 E$ ). Together, our data demonstrate that the odorant receptor mRNAs quantified with our RT-qPCR assay on crude olfactory bulb extracts are compartmentalized in sensory neuron axons.

Next, we quantified odorant receptor mRNAs during the perinatal period, during which olfactory bulbs in the process of forming the glomerular array contain a large number of in-growing and immature GAP43-positive sensory axons (Pomeroy et al., 1990; Treloar et al., 1999). We observed that the olfactory system is still highly immature at P4, as demonstrated by the GAP43 mRNA/ OMP mRNA ratio in the olfactory mucosa $(1.06 \pm 0.05$, as opposed to the 0.2 observed in the adult) (Fig. 1C). We decided to use this developmental stage to prepare and analyze olfactory bulb polysomes (see below). At this stage, the expression of odorant receptor genes in the olfactory epihelium is much lower than that found in adults (Fig. 2A). Surprisingly, however, the quantities of all three examined odorant receptor mRNAs in $\mathrm{P} 4$ bulbs appear to be of the same order of magnitude as in adults (Fig. 2B), indicating that the axonal transport of odorant receptor mRNAs is higher in P4 than in adults. Calculation of the "relative bulb/ epithelium transport index," which represents an estimate of the percentage of mRNA molecules transported in bulbar sensory axons compared with that present at equilibrium in the overall population of sensory neuron cell bodies, showed that these indexes are 5- to 8.7-fold higher (depending on the odorant receptor examined) in $\mathrm{P} 4$ mice in comparison with adults (Fig. 2C). These data suggest that the axonal transport of odorant receptor mRNAs is developmentally regulated, and negatively correlated with the degree of maturity of the olfactory sensory neuron population.

We then investigated whether these mRNAs are translated in axons by analyzing their association with polysomal fractions (Bagni et al., 2000). To this end, we fractionated olfactory bulb 
A

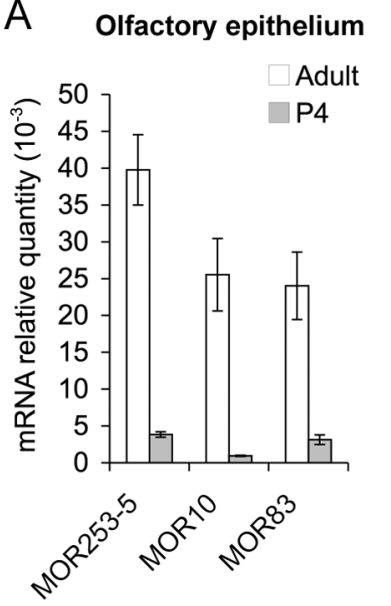

B
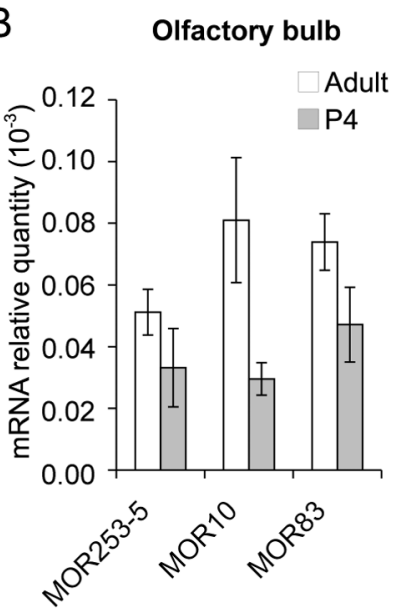

C

Relative OB/OE transport index (\%)

\begin{tabular}{cccc} 
& MOR253-5 & MOR10 & MOR83 \\
\hline $\begin{array}{c}\text { Adult } \\
\text { P4 }\end{array}$ & $0.13 \pm 0.02$ \\
$0.87 \pm 0.32$
\end{tabular} \mid * $\begin{gathered}0.35 \pm 0.06 \\
3.09 \pm 0.41\end{gathered}\left|* \begin{array}{c}0.32 \pm 0.03 \\
1.63 \pm 0.46\end{array}\right|$ *

Figure 2. Developmentally regulated transport of odorant receptor mRNAs in axons of olfactory sensory neurons. A, RT-qPCR quantification of MOR253-5, MOR83, and MOR10 mRNAs from adult and P4 mice olfactory epithelium. $B$, RT-qPCR quantification of MOR253-5, MOR83, and MOR10 mRNAs from adult or P4 mice olfactory bulb. $C$, Relative olfactory bulb/olfactory epithelium $(\mathrm{OB} / \mathrm{OE})$ transport index for odorant receptor $m R N A s$, representing the percentage of odorant receptor mRNAs quantified in the olfactory bulb over the percentage quantified in the olfactory epithelium. These indices are higher in P4 mice than in adult mice, indicating a greater axonal transport in sensory axons at P4 than in adults. Data are expressed as mean \pm SEM $(n=4-5)$. * Mann-Whitney U test: $p=0.016$ for MOR10, $p=0.029$ for M0R253-5 and MOR83. All RT-qPCR data were normalized using $\alpha 1 \mathrm{~b}$-Tubulin mRNA as an internal standard.

extracts on a $5-60 \%$ continuous sucrose gradient and separated the dense polysomal fractions from the light mRNP fractions (Fig. 3A). We then quantified the selected odorant receptor mRNA distribution in these fractions. The association of mRNAs with the polysomes is expressed as the percentage of mRNA on polysomes (PMP). In adult olfactory bulbs, significant levels of odorant receptor mRNAs are associated with polysomes (PMP, $11.83 \pm 6.53$ to $41.38 \pm 4.73$, depending on the examined odorant receptors) (Fig. 3B). This association to polysomes is specific, because polysome dissociation using EDTA treatment leads to a dramatic shift of odorant receptor mRNA from the bottom to top fractions (supplemental Fig. 1, available at www.jneurosci.org as supplemental material). In addition, both the absorbance profiles (Fig. 3A) and the expected translation level for the untransported mRNA, $\alpha 1$ b-Tubulin (mean PMP, $70.7 \pm 2.5 \%$ ), suggested that the adult olfactory bulb polysome preparations were successful. Interestingly, the relatively low PMPs characterizing odorant receptor mRNAs in the adult olfactory bulb are not an intrinsic feature of these mRNAs since the PMPs for these mRNAs reach $76.31 \pm 1.49$ to $92.75 \pm 1.67$ in the olfactory epithelium, depending on the odorant receptor examined. In P4 mice, a substantial increase in olfactory bulb PMPs is observed for all three analyzed odorant receptors (1.5-fold for MOR10, 2.2-fold for MOR253-5, and 3.2-fold for MOR83).

Our data appear to suggest that the overall translation rate of odorant receptor mRNAs is higher in immature than in mature olfactory bulbs. To further explore this hypothesis, we examined
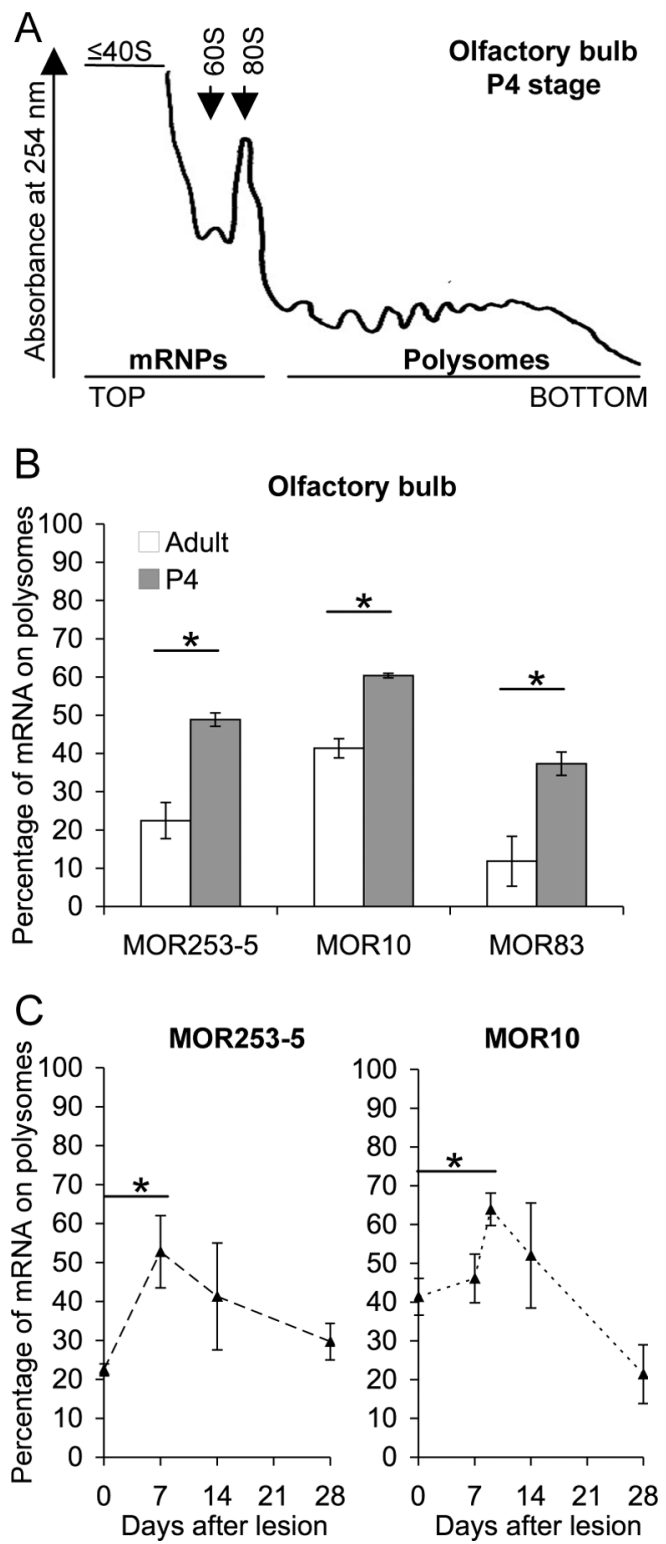

Figure 3. Developmentally regulated translation of odorant receptor mRNAs in bulbar sensory axons. $A$, Typical polysomal profile obtained in a sucrose gradient fractionation of olfactory bulb. $B, C, 0$ dorant receptor $m R N A$ s were quantified in both $\mathrm{mRNP}$ and polysome fractions from olfactory bulb, and the PMP was calculated for each of them. Data are expressed as mean \pm SEM. B, MOR253-5, MOR83, and MOR10 PMPs in olfactory bulb from adult and P4 mice. PMPs for odorant receptor mRNA in the bulb are higher in P4 than in adult mice. * Mann-Whitney $U$ test: $p=0.052$ for MOR10 $(n=5-6), p=0.057$ for M0R253-5 and MOR83 $(n=3-4)$. C, MOR253-5 and MOR10 PMPs in olfactory bulb from adult mice after dichlobenil treatment (refer to Fig. $1 \mathrm{~A}$ for the dichlobenil experiment protocol). A transitory increase in MOR253-5 and MOR10 PMPs is observed at days 7 and 9 , respectively, before PMPs return to lower values by day 28. *Mann-Whitney $U$ test: $p=0.057$ for MOR253-5 $(n=3-4), p=0.038$ for MOR10 $(n=4-6)$.

the odorant receptor PMPs during the regeneration of the olfactory projection after dichlobenil-mediated sensory neuron lesions. In this paradigm, PMPs for MOR83 mRNA were impossible to accurately assess at days 7-14 because of the very low levels of mRNA remaining in the bulb after the lesion of the epithelium (Fig. 1E). We therefore restricted this part of the study to the MOR253-5 and MOR10 mRNAs, which were measurable (Fig. 3C). Whereas the level of $\alpha 1 \mathrm{~b}-$ Tubulin translation in the olfactory bulb was not significantly affected at any stage after 
A

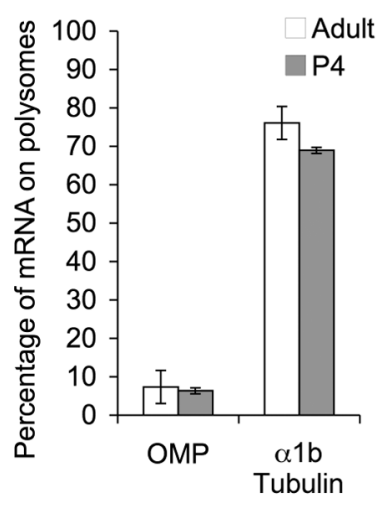

B

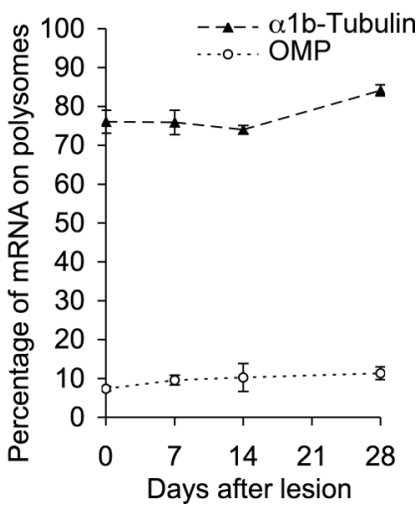

Figure 4. OMP mRNA local translation in bulbar sensory axons is not higher in P4 mice than in adult mice, and it does not increase in the regeneration process after dichlobenil lesion. $\boldsymbol{A}, 0 \mathrm{MP}$ and $\alpha 1 \mathrm{~b}$-Tubulin PMPs in bulbs from adult and P4 mice. $\boldsymbol{B}, 0 \mathrm{MP}$ and $\alpha 1 \mathrm{~b}$-Tubulin PMPs in olfactory bulbs from adult mice on dichlobenil treatment. PMPs for OMP mRNA are equally low $(\sim 10 \%)$ in all tested conditions. OMP and $\alpha 1 \mathrm{~b}$-Tubulin mRNAs were quantified in both mRNP and polysome fractions from olfactory bulbs, and the PMP was calculated for each of them. Data are expressed as mean $\pm \operatorname{SEM}(n=4)$.

lesion (Fig. 4B), MOR253-5 and MOR10 PMPs exhibit a substantial increase during the second week after the first dichlobenil injection, before they progressively returned to lower values by day 28. These data further support our hypothesis, which proposes a link between the immaturity of sensory neuron axons and the level of axonal odorant receptor translation.

We then asked whether these data obtained for odorant receptor mRNAs apply to the OMP mRNA, which is also known to be transported into sensory neuron axons (Vassar et al., 1994; Wensley et al., 1995). As for odorant receptor mRNAs, significant amounts of OMP mRNA are associated to polysomes in the adult olfactory bulb (Fig. $4 A$ ), indicating that a subset of OMP mRNA molecules are actually translated in sensory neuron axons in adult mice. However, the low PMP for OMP (7.34 \pm $4.30 \%$ ) indicated that the translation rate of OMP mRNA was lower than that of the three odorant receptor mRNAs examined in this study. Strikingly, no significant difference was found in OMP mRNA translation levels between P4 and normal adults (Fig. $4 A$ ), as well as in the dichlobenil-treated mice at all regeneration stages (Fig. $4 B$ ). In conclusion, in contrast to odorant receptor mRNAs, there is no developmental regulation of OMP mRNA translation in sensory neuron axons.

\section{Discussion}

The presence of odorant receptor mRNAs in axons of olfactory sensory neurons was first reported 15 years ago (Ressler et al., 1994; Vassar et al., 1994). However, the functional relevance of this extrasomatic localization of mRNA remains unclear. The main objectives of the present study were to measure axonal transport indices for several odorant receptor mRNAs and to determine whether these mRNAs are translated in axons using a powerful biochemical approach. Since it is not possible to purify sensory neuron axons from the mouse olfactory bulb, we designed a method that involves the RT-qPCR analysis of biochemical fractions prepared from whole bulbs. Therefore, it was critical to verify that the odorant receptor mRNAs quantified from olfactory bulb extracts or biochemical fractions were axonally compartmentalized. We unambiguously showed that they originate from the olfactory sensory neurons located in the olfactory epithelium by demonstrating that chemical lesion of sensory

neurons transiently removes a large part of these mRNAs from the bulb, correlated with the degeneration and regeneration of sensory axons. Therefore, we assume that all the odorant receptor mRNAs quantified in our experiments from olfactory bulb crude extracts or biochemical fractions are of axonal origin. This axonal population contains both immature and mature axons in all tested conditions - even in adult mice-because of the continuous neurogenesis occurring in the olfactory epithelium.

We first analyzed crude olfactory bulb and epithelium extracts from adult and $\mathrm{P} 4$ mice, and calculated the axonal transport index for three odorant receptor mRNAs in both groups of animals. We report higher transport indices for odorant receptor mRNAs at $\mathrm{P} 4$ than in adult, demonstrating that the axonal transport of odorant receptor mRNAs is greater in an immature olfactory system compared with a mature one. This finding can be interpreted in two ways that are not mutually exclusive: a larger transport per axon, and/or a greater amount of axons transporting the mRNA. Given the established functions of axonal mRNAs in axon growth and guidance (Lin and Holt, 2007), it is tempting to interpret this difference as the result of a greater transport of odorant receptor mRNAs in developing olfactory sensory axons than in mature ones. High-resolution in situ hybridization studies that combine the detection of odorant receptor mRNAs and maturation markers (as GAP43 and OMP) are required to definitively identify the axons transporting odorant receptor mRNAs, and to assess the degree of axonal transport of odorant receptor mRNAs in immature versus mature axons.

We observed that a significant amount of odorant receptor mRNAs was present in polysome-containing high-density fractions prepared from olfactory bulbs. This association was specific and polysome dependent, since disruption of polysomes with EDTA leads to a dramatic reduction of odorant receptor mRNA concentration in bottom fractions. Hence, we provide the first evidence for a local synthesis of odorant receptor proteins in the axon of olfactory sensory neurons. Whether the association of odorant receptor mRNAs to polysomes leads to the synthesis of functional odorant receptor proteins properly addressed to the plasma membrane of the axons is currently unknown. Even though strong evidence for the presence of functional odorant receptors at growth cone/axon termini surface of olfactory sensory neurons was recently obtained ex vivo and in a hemihead preparation (Maritan et al., 2009), it remains unknown whether these odorant receptors have a local origin. Although the presence of a functional secretory machinery in mature axons is controversial, evidence for the local synthesis of several membrane proteins in developing axons has been reported (Brittis et al., 2002; Bi et al., 2006), and the presence of a functional equivalent of endoplasmic reticulum and Golgi in retinal ganglion cell growth cones has been documented (Merianda et al., 2009). It thus appears very likely that locally synthesized membrane proteins can be inserted into the plasma membrane in growing axons.

Olfactory bulb PMPs in untreated adult mice vary significantly from one odorant receptor mRNA species to another (from 11 to $41 \%$ ) for reasons not well understood. Likewise, PMP values for odorant receptor mRNAs at $\mathrm{P} 4$ and also during the regeneration process after lesion differ from one odorant receptor to another. It is well known that variation across odorant receptor gene expression in mice is the rule rather than the exception in terms of expression levels, number of sensory neurons expressing an odorant receptor gene, and the time of onset of expression during development (for review, see Mombaerts, 2006). Differences in these parameters may thus participate in causing differences in translation levels across distinct axonal 
odorant receptor mRNAs populations. In addition, if the translation of mRNAs mainly occurs in growing/immature axons in this system, differential turnover between sensory neurons expressing different odorant receptors may also result in differences in the global PMPs measured within the olfactory bulb.

A translational feature shared by all three odorant receptor mRNAs analyzed in this work is that, in all circumstances (P4, as well as untreated or lesioned adults), the proportion of axonal odorant receptor mRNAs associated with polysomes is lower than that observed in the olfactory epithelium. This finding strongly indicates that a significantly larger pool of odorant receptor mRNA is in a repressed state in axons, probably because of the fact that axonal transport of mRNAs from the cell body requires packaging of mRNAs into granules and translational repression during transport (Kiebler and Bassell, 2006; Sossin and DesGroseillers, 2006). Future studies addressing the molecular composition of these odorant receptor mRNA granules will help reveal the molecular mechanisms used for transport and translational repression/activation of these mRNAs in axons of olfactory sensory neuron.

The main result of this study is that we have demonstrated that the translation of odorant receptor mRNAs in the axons of olfactory sensory neurons is developmentally regulated. At an early postnatal stage, as well as in the context of olfactory sensory neuron regeneration after lesion, we measured higher rates of translation for these mRNAs, indicating a functional relationship between axonal translation of odorant receptor mRNAs and the development of the sensory projections. In line with this hypothesis, the percentage of mRNA on polysomes as a function of the maturation index of the olfactory system (assessed by a ratio of OMP mRNA to GAP43 mRNA in the olfactory epithelium) (Fig. $5 A-D)$ shows that the more the system matures (100\% maturity corresponding to the adult situation), the less odorant receptor mRNAs are translated (Fig. $5 A, B$ ). In contrast, this is not the case for an untransported mRNA expressed in olfactory bulb cells ( $\alpha 1 \mathrm{~b}$-Tubulin) or, more importantly, for the OMP mRNA known to be confined to mature sensory axons (Fig. $5 C, D$ ). These findings support a theory that translation rates for odorant receptor mRNAs may be higher in immature axons than in mature ones.

What is the potential role of the local translation of odorant receptor mRNAs in olfactory axons? Previous work using either genetically expressed tagged-odorant receptors (Feinstein et al., 2004) or antibodies against endogenous odorant receptors (Barnea et al., 2004; Strotmann et al., 2004) reported the presence of these proteins in sensory axons within the olfactory nerve layer and glomeruli. Interestingly, no detectable endogenous odorant receptor immunoreactivity was observed in the more proximal bundles of the sensory axons, located in between the epithelium and the bulb (Barnea et al., 2004; Strotmann et al., 2004). It is now well established that odorant receptor proteins are involved in olfactory axon guidance (for review, see Mombaerts, 2006) and that homotypic fasciculation of sensory axons expressing the same odorant receptor may take place within the olfactory nerve layer (Treloar et al., 2002). Our data, which indicates that odorant receptor mRNAs are locally translated in sensory axons in the bulb, may explain their particular compartmentalization in the distal-most part of these axons. In light of the known functions of odorant receptors in the guidance of olfactory axons, it is tempting to speculate that their regulated local synthesis in axons may play a role in this process, by allowing them to acquire their odorant receptor identity as they extend into the bulb. It will be critical to determine the contribution of such a hypothetical mechanism in the glomerular array formation, with respect to the
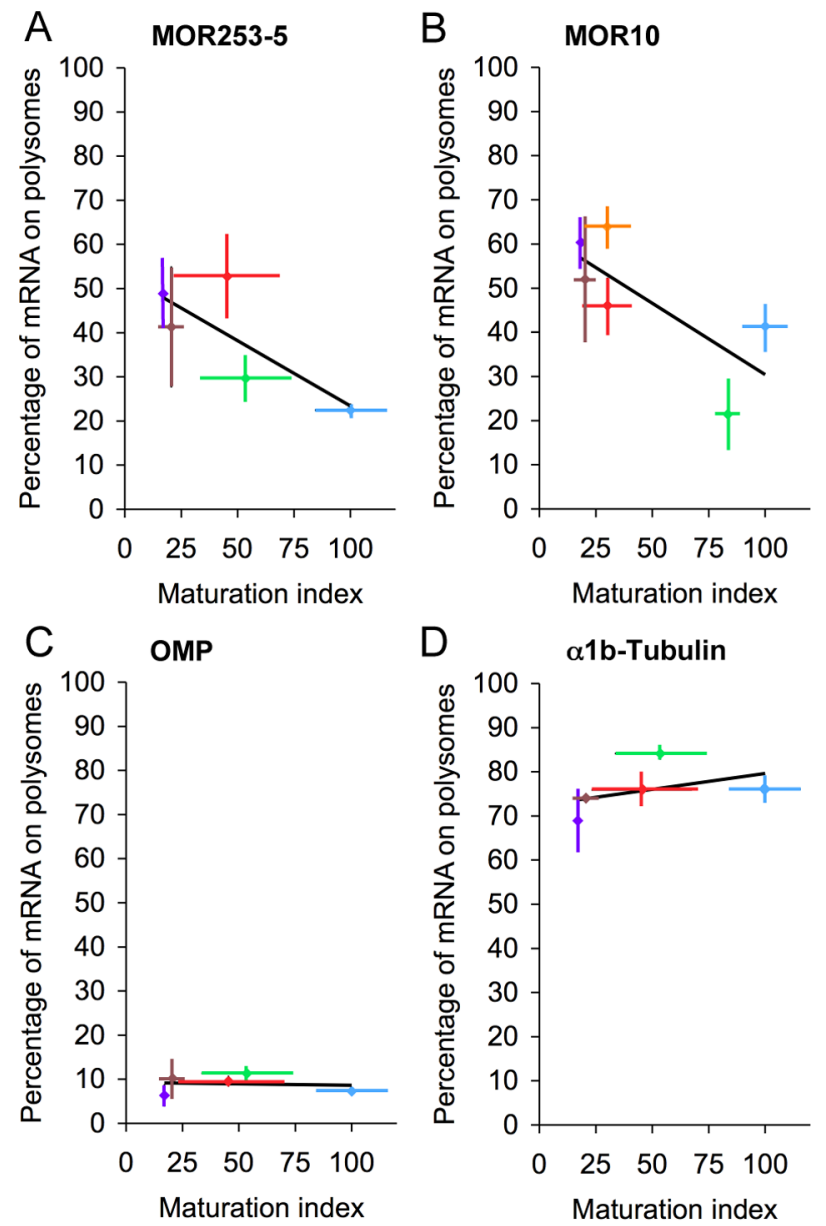

\begin{tabular}{|c|c|}
\hline $\begin{array}{l}\text { Adult (control) } \\
\text { Dichlobenil - } 7 \text { days } \\
\text { Dichlobenil - } 9 \text { days }\end{array}$ & $\begin{array}{l}\text { Dichlobenil - } 14 \text { days } \\
\text { Dichlobenil - } 28 \text { days } \\
\text { P4 }\end{array}$ \\
\hline
\end{tabular}

Figure 5. Odorant receptor and OMP mRNAs local translation in bulbar sensory axons are differentially regulated. Correlation between sensory neuron maturation indices (calculated from 0MP/GAP43 mRNAs ratio in the olfactory epithelium; the value for untreated adult mice is $100 \%$ ) and PMPs for the M0R253-5 (A), MOR10 (B), OMP (C), and $\alpha 1$ b-Tubulin (D) mRNAs in the olfactory bulb in various physiological or experimental conditions: P4 (purple); untreated adults (blue); adults after dichlobenil treatment ( $7 \mathrm{~d}$ after the onset of dichlobenil treatment in red, $9 \mathrm{~d}$ in orange, $14 \mathrm{~d}$ in brown, $28 \mathrm{~d}$ in green). Linear trend lines are shown for each mRNA (slope: MOR253-5, -29.6; MOR10, -32.3;0MP, $-0.6 ; \alpha 1 \mathrm{~b}$-Tubulin, 7.2).

recently established role of the odorant receptor/Gs/cAMP cascade regulating the transcription of adhesion and guidance molecules involved in axon-axon interactions (Imai et al., 2006; Serizawa et al., 2006; Chesler et al., 2007; Maritan et al., 2009).

\section{References}

Bagni C, Mannucci L, Dotti CG, Amaldi F (2000) Chemical stimulation of synaptosomes modulates $\alpha$ - $\mathrm{Ca}^{2+} /$ calmodulin-dependent protein kinase II mRNA association to polysomes. J Neurosci 20:RC76(1-6).

Barnea G, O’Donnell S, Mancia F, Sun X, Nemes A, Mendelsohn M, Axel R (2004) Odorant receptors on axon termini in the brain. Science 304:1468.

Bi J, Tsai NP, Lin YP, Loh HH, Wei LN (2006) Axonal mRNA transport and localized translational regulation of kappa-opioid receptor in primary neurons of dorsal root ganglia. Proc Natl Acad Sci U S A 103:19919-19924.

Brittis PA, Lu Q, Flanagan JG (2002) Axonal protein synthesis provides a mechanism for localized regulation at an intermediate target. Cell 110:223-235.

Brunet I, Weinl C, Piper M, Trembleau A, Volovitch M, Harris W, Prochiantz A, 
Holt C (2005) The transcription factor Engrailed-2 guides retinal axons. Nature 438:94-98.

Buck L, Axel R (1991) A novel multigene family may encode odorant receptors: a molecular basis for odor recognition. Cell 65:175-187.

Campbell DS, Holt CE (2001) Chemotropic responses of retinal growth cones mediated by rapid local protein synthesis and degradation. Neuron 32:1013-1026.

Chesler AT, Zou DJ, Le Pichon CE, Peterlin ZA, Matthews GA, Pei X, Miller MC, Firestein S (2007) A G protein/cAMP signal cascade is required for axonal convergence into olfactory glomeruli. Proc Natl Acad Sci U S A 104:1039-1044.

Cox LJ, Hengst U, Gurskaya NG, Lukyanov KA, Jaffrey SR (2008) Intraaxonal translation and retrograde trafficking of CREB promotes neuronal survival. Nat Cell Biol 10:149-159.

Feinstein P, Bozza T, Rodriguez I, Vassalli A, Mombaerts P (2004) Axon guidance of mouse olfactory sensory neurons by odorant receptors and the beta2 adrenergic receptor. Cell 117:833-846.

Giuditta A, Chun JT, Eyman M, Cefaliello C, Bruno AP, Crispino M (2008) Local gene expression in axons and nerve endings: the glia-neuron unit. Physiol Rev 88:515-555.

Hillefors M, Gioio AE, Mameza MG, Kaplan BB (2007) Axon viability and mitochondrial function are dependent on local protein synthesis in sympathetic neurons. Cell Mol Neurobiol 27:701-716.

Imai T, Suzuki M, Sakano H (2006) Odorant receptor-derived cAMP signals direct axonal targeting. Science 314:657-661.

Kiebler MA, Bassell GJ (2006) Neuronal RNA granules: movers and makers. Neuron 51:685-690.

Klenoff JR, Greer CA (1998) Postnatal development of olfactory receptor cell axonal arbors. J Comp Neurol 390:256-267.

Leung KM, van Horck FP, Lin AC, Allison R, Standart N, Holt CE (2006) Asymmetrical beta-actin mRNA translation in growth cones mediates attractive turning to netrin-1. Nat Neurosci 9:1247-1256.

Lin AC, Holt CE (2007) Local translation and directional steering in axons. EMBO J 26:3729-3736.

Mackay-Sim A, Kittel PW (1991) On the life span of olfactory receptor neurons. Eur J Neurosci 3:209-215.

Maritan M, Monaco G, Zamparo I, Zaccolo M, Pozzan T, Lodovichi C (2009) Odorant receptors at the growth cone are coupled to localized cAMP and $\mathrm{Ca}^{2+}$ increases. Proc Natl Acad Sci U S A 106:3537-3542.

Merianda TT, Lin AC, Lam JS, Vuppalanchi D, Willis DE, Karin N, Holt CE, Twiss JL (2009) A functional equivalent of endoplasmic reticulum and Golgi in axons for secretion of locally synthesized proteins. Mol Cell Neurosci 40:128-142.

Mombaerts P (2004) Odorant receptor gene choice in olfactory sensory neurons: the one receptor-one neuron hypothesis revisited. Curr Opin Neurobiol 14:31-36.

Mombaerts P (2006) Axonal wiring in the mouse olfactory system. Annu Rev Cell Dev Biol 22:713-737.

Mori K, Nagao H, Yoshihara Y (1999) The olfactory bulb: coding and processing of odor molecule information. Science 286:711-715.

Nédélec S, Foucher I, Brunet I, Bouillot C, Prochiantz A, Trembleau A (2004) Emx2 homeodomain transcription factor interacts with eukaryotic translation initiation factor $4 \mathrm{E}$ (eIF4E) in the axons of olfactory sensory neurons. Proc Natl Acad Sci U S A 101:10815-10820.
Nédélec S, Dubacq C, Trembleau A (2005) Morphological and molecular features of the mammalian olfactory sensory neuron axons: what makes these axons so special? J Neurocytol 34:49-64.

Pomeroy SL, LaMantia AS, Purves D (1990) Postnatal construction of neural circuitry in the mouse olfactory bulb. J Neurosci 10:1952-1966.

Ressler KJ, Sullivan SL, Buck LB (1994) Information coding in the olfactory system: evidence for a stereotyped and highly organized epitope map in the olfactory bulb. Cell 79:1245-1255.

Roche FK, Marsick BM, Letourneau PC (2009) Protein synthesis in distal axons is not required for growth cone responses to guidance cues. J Neurosci 29:638-652.

Schwob JE (2005) Restoring olfaction: a view from the olfactory epithelium. Chem Senses 30 [Suppl 1]:i131-i132.

Serizawa S, Miyamichi K, Takeuchi H, Yamagishi Y, Suzuki M, Sakano H (2006) A neuronal identity code for the odorant receptor-specific and activity-dependent axon sorting. Cell 127:1057-1069.

Sossin WS, DesGroseillers L (2006) Intracellular trafficking of RNA in neurons. Traffic 7:1581-1589.

Strotmann J, Levai O, Fleischer J, Schwarzenbacher K, Breer H (2004) Olfactory receptor proteins in axonal processes of chemosensory neurons. J Neurosci 24:7754-7761.

Treloar HB, Purcell AL, Greer CA (1999) Glomerular formation in the developing rat olfactory bulb. J Comp Neurol 413:289-304.

Treloar HB, Feinstein P, Mombaerts P, Greer CA (2002) Specificity of glomerular targeting by olfactory sensory axons. J Neurosci 22:2469-2477.

Trembleau A, Morales M, Bloom FE (1994) Aggregation of vasopressin mRNA in a subset of axonal swellings of the median eminence and posterior pituitary: light and electron microscopic evidence. J Neurosci 14:39-53.

Tsuboi A, Yoshihara S, Yamazaki N, Kasai H, Asai-Tsuboi H, Komatsu M, Serizawa S, Ishii T, Matsuda Y, Nagawa F, Sakano H (1999) Olfactory neurons expressing closely linked and homologous odorant receptor genes tend to project their axons to neighboring glomeruli on the olfactory bulb. J Neurosci 19:8409-8418.

Vassar R, Chao SK, Sitcheran R, Nuñez JM, Vosshall LB, Axel R (1994) Topographic organization of sensory projections to the olfactory bulb. Cell 79:981-991.

Wensley CH, Stone DM, Baker H, Kauer JS, Margolis FL, Chikaraishi DM (1995) Olfactory marker protein mRNA is found in axons of olfactory receptor neurons. J Neurosci 15:4827-4837.

Willis DE, Twiss JL (2006) The evolving roles of axonally synthesized proteins in regeneration. Curr Opin Neurobiol 16:111-118.

Wu KY, Hengst U, Cox LJ, Macosko EZ, Jeromin A, Urquhart ER, Jaffrey SR (2005) Local translation of RhoA regulates growth cone collapse. Nature 436:1020-1024.

Yao J, Sasaki Y, Wen Z, Bassell GJ, Zheng JQ (2006) An essential role for beta-actin mRNA localization and translation in $\mathrm{Ca}^{2+}$-dependent growth cone guidance. Nat Neurosci 9:1265-1273.

Yoon H, Enquist LW, Dulac C (2005) Olfactory inputs to hypothalamic neurons controlling reproduction and fertility. Cell 123:669-682.

Zhang X, Rogers M, Tian H, Zhang X, Zou DJ, Liu J, Ma M, Shepherd GM, Firestein SJ (2004) High-throughput microarray detection of olfactory receptor gene expression in the mouse. Proc Natl Acad Sci U S A 101: $14168-14173$. 